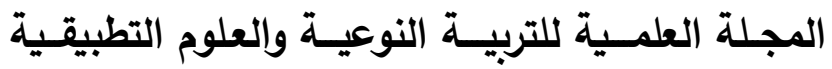

The Scientific Journal of Specific Education and Applied Sciences

\title{
Effect of Pomegranate Juice against High Fat Diet Induced Fatty Liver in rats
}

\author{
Soha M. Yousef \\ Nutrition \& Food Sciences, Department of Home Economics, \\ Faculty of Specific Education, Fayoum University, Egypt.
}

\section{Abstract}

This research aims at studying the effect of pomegranate juice against high fat diet induced fatty liver in rats. Forty adult male rats Sprague-Dawley strain, were divided into four groups of ten rats each weighing $180 \pm 20 \mathrm{~g}$. (G1) control group that were fed on standard diet, (G2) rats fed on standard diet with Pomegranate juice $(20 \mathrm{ml} / \mathrm{kg}$ body weight orally), (G3) rats fed on high fat diet, (G4) rats fed on high fat diet with pomegranate juice (20 $\mathrm{ml} / \mathrm{kg}$ body weight orally). The experiment was conducted for 6 weeks. The incidence of fatty liver was evaluated by assayed the liver enzymes in serum (alanine aminotransferase and aspartate aminotransferase), serum lipid profile such as total cholesterol, high density lipoprotein cholesterol, triglycerides and histopathological examination of liver. The high fat diet group (G3), revealed hyperlipidemia, elevated in liver enzymes and histological changes in the liver tissue. While, the rats fed high fat diet with pomegranate juice group (G4), showed reduction in the levels of serum lipids and improvement in the liver enzymes. Furthermore, pomegranate juice reduced the occurrence of histological changes in rat's liver. The results of the study concluded that daily administration of pomegranate juice can protect against developing changes caused by high fat diet and reduced the development of fatty liver. These findings suggested that drinking pomegranate juice may be beneficial for people who are exposed to fatty liver or hypercholesterolemia.

Keywords: pomegranate juice, fatty liver, high fat diet, rats. 


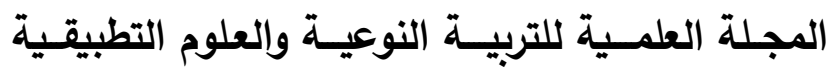

The Scientific Journal of Specific Education and Applied Sciences

\section{Introduction:}

The liver is the largest organ in the body, which plays a vital role, performing many complex functions essential for life. The liver manufactures proteins, processes carbohydrates, and absorbs fat products and makes them available as fuel. The liver serves as a storehouse of vitamins and minerals and processes iron for the blood system. Any injury to liver disturbs the body's capacity to use food nutrients and has a devastating effect on the wellbeing of the person (Mudambi and Rajagopal, 2007).

Fatty liver disease is a condition where excess fat accumulation in the liver. There are two types' non-alcoholic fatty liver disease (NAFLD) and alcoholic liver disease (Iser and Ryan, 2013). Nonalcoholic fatty liver disease is being known as a common liver disorder that represents the hepatic manifestation of the metabolic syndrome, a variably defined aggregate of disorders related to obesity, insulin resistance, type II diabetes, hypertension and hyperlipidemia (Brunt, 2004). NAFLD is clinically important due to its pathological changes in the liver which can progress to cirrhosis, hepatocellular carcinoma and even liver failure with increased hepatic-related mortality (Korish and Arafah, 2013). The prevalence of NAFLD has reached epidemic proportions in recent years in line with the increasing prevalence of obesity. NAFLD is an early warning sign of future risk for type II diabetes and cardiovascular disease (Tan et al., 2013).

Punica granatum (pomegranate) is one of the oldest edible fruits and cultivated in the Mediterranean and Asian countries. Polyphenols, flavonoids and anthocyanin are the compounds in pomegranate regarded as strong antioxidants. Pomegranate has had so many applications in traditional medicine (Lansky and Newman, 2007). Pomegranate has many biological activities such as anticarcinogenic, antibacterial, antidiarrheal, antifungal, antinephrolithiasis and antigastric ulceration effects. It could modify the risk of hypercholesterolemia and has protective properties on the skin (Agha et al., 2013).

Pomegranate juice is composed of water (85\%), sugar (10\%), pectin, ascorbic acid and polyphenols (1.5\%) (Aviram et al., 2000). The beneficial effects of pomegranate juice on human health arise from the strong antioxidants in its content (Rosenblat et al., 2006). This study aimed to investigate the effect of 


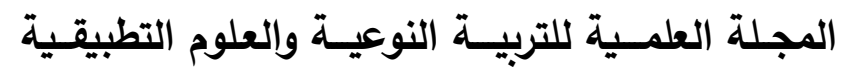

The Scientific Journal of Specific Education and Applied Sciences

pomegranate juice against high fat diet induced fatty liver disease in male rats.

\section{Materials and Methods:}

Experimental animals: Forty adult male rats, weighing $(180 \pm 20 \mathrm{~g})$ at the beginning of the experiments were purchased from the laboratory of animals colony, The National Center for Researches, Cairo, Egypt . The rats were kept under standard laboratory condition. They were allowed food and water ad libitum. They were provided with a nutritionally adequate standard diet. Standard diet was prepared according to (Philp et al., 1993).

Preparation of the high fat diet: The high-fat diet has been prepared according to (Jiayin et al., 2011). 20\% animal fat $+1 \%$ cholesterol was added to standard diet.

Preparation of pomegranate juice: The pomegranates were washed, peeled, squeezed using blender and filtered to remove the pickings. The juice was made daily and refrigerated until use.

Experimental design: After accommodation one week, the 40 rats were divided randomly into four groups of 10 rats each:

Group1: (control group) rats fed on standard diet.

Group2: rats fed on standard diet + Pomegranate juice $(20 \mathrm{ml} / \mathrm{kg}$ body weight) orally.

Group3: rats fed on high fat diet.

Group4: rats fed on high fat diet + Pomegranate juice $(20 \mathrm{ml} / \mathrm{kg}$ body weight) orally. Ethical guidelines were maintained in animal handling during the study and permission was obtained from the concerned department.

The experiment was conducted for 6 weeks. At the end of the experiment, the rats were fasted overnight then sacrificed under anesthesia. Blood samples of rats were centrifuged at 3000 rpm for 15 minutes. Serum samples were carefully separated and stored at $-20{ }^{\circ} \mathrm{c}$ for biochemical analysis. After animal sacrificed and blood samples collected, the liver of the experimental animals were removed, washed with saline solution and dried with filter paper. A portion of the liver of each animal were kept in $10 \%$ formalin for the histological study. 


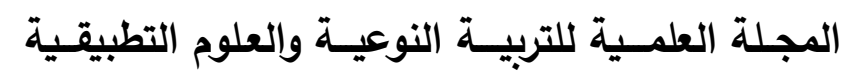

The Scientific Journal of Specific Education and Applied Sciences

Biochemical analysis: Serum total cholesterol was determined according to (Charles et al., 1974). High density lipoprotein cholesterol was determined according to (Lopes et al., 1977). Serum triglycerides (TGs) were determined according to (Fossati and Prencipe, 1982). Serum alanine aminotransferase (ALT) activity was assayed according to (Srivastava et al., 2002). Serum aspartate aminotransferase (AST) activity was assayed according to (Schumann and Klauke, 2003). All biochemical analysis were analyzed using diagnostic kits produced by Spectrum (Egyptian Company for Biotechnology).

Histopathological examination on liver: A portion of the liver of each rat were placed in buffered $10 \%$ formalin solution for fixation and preservation. The samples of liver were embedded in paraffin and prepared for histological examination by sectioning and staining with hematoxylin and eosin according to (Drury and Wallington, 1980). Histological studies were monitored by microscopic examination of paraffin embedded slices of liver.

Statistical analysis: All data were expressed as mean \pm standard deviation (SD). Statistical analyses were carried out using SPSS software. The difference among groups was analyzed by one-way (ANOVA) and T- test. $\mathrm{p}<0.05$ was considered statistical significant (Waller and Duncan, 1969).

\section{Results \& Discussion:}

As shown in table (1) the pomegranate juice group (G2) showed no significant change in the levels of total cholesterol, high density lipoprotein and triglycerides as compared to the control group (G1). While the high fat diet group (G3) revealed statistical significant elevation in levels of total cholesterol, triglycerides and significant reduction in high density lipoprotein levels as compared to the control group (G1). High fat diet + pomegranate juice group (G4) showed significantly reduction in the levels of total cholesterol, triglycerides and significantly elevation in level of high density lipoprotein as compared to high fat diet group (G3). This group (G4) showed no significant change in lipid profile in comparison with the control group (G1). 


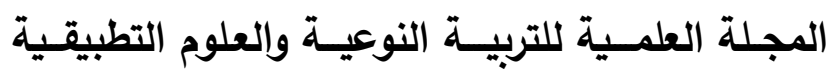

The Scientific Journal of Specific Education and Applied Sciences

Table 1. Serum levels of total cholesterol, high density lipoprotein and triglycerides of the experimental rat groups.

\begin{tabular}{|c|c|c|c|c|}
\hline Parameters & $\begin{array}{c}\text { G1 } \\
\text { control } \\
\text { group }\end{array}$ & $\begin{array}{c}\text { G2 } \\
\text { PJ }\end{array}$ & $\begin{array}{c}\text { G3 } \\
\text { HFD }\end{array}$ & $\begin{array}{c}\text { G4 } \\
\text { HFD + PJ }\end{array}$ \\
\hline $\begin{array}{c}\text { Total } \\
\text { cholesterol } \\
\text { (mg/dl) }\end{array}$ & $77.56 \pm 6.17$ & $83.2 \pm 7.11$ & $163.54 \pm 9.23^{* *}$ & $89.38 \pm 7.01^{++}$ \\
\hline $\begin{array}{c}\text { High density } \\
\text { lipoprotein } \\
\text { (mg/dl) }\end{array}$ & $45.25 \pm 5.45$ & $46.62 \pm 6.32$ & $32.56 \pm 5.51^{* *}$ & $44.23 \pm 5.90^{++}$ \\
\hline $\begin{array}{c}\text { Triglycerides } \\
\text { (mg/dl) }\end{array}$ & $80.89 \pm 14.74$ & $81.02 \pm 13.82$ & $142.52 \pm 15.04^{* *}$ & $85.01 \pm 12.31^{++}$ \\
\hline
\end{tabular}

Comparison between experimental groups as regard mean $\pm \mathrm{SD}(\mathrm{n}=10)$. Values are statistically significant at ${ }^{* *}$ p $<0.01$ versus $\mathrm{G} 1 ;{ }^{*} \mathrm{p}<0.05$ versus $\mathrm{G} 1 ;{ }^{++} \mathrm{p}<$ 0.01 versus G3; ${ }^{+} \mathrm{p}<0.05$ versus G3;. PJ: Pomegranate juice; HFD: high fat diet.

The results of the study showed that feeding rats on highfat diet caused significant elevation in the serum levels of total cholesterol and triglycerides accompanied by significant reduction in levels of high density lipoprotein compared with control group. These results are consistent with (Lim et al., 2013) who demonstrated that feeding rats with high-fat diet leads to elevation in absorption of cholesterol and hence elevation in serum cholesterol and triglycerides. Also, (Shepherd, 1994) elucidated that reduction in the levels of high density lipoprotein in animals feeding high-fat diet might because the reduction in the enzyme responsible for trans esterification of cholesterol, the maturation of HDL and the flux of cholesterol from cell membranes into HDL.

In the present study, it was observed that pomegranate juice with high-fat diet limit of lipid profile alterations. These results consistent with the findings of (Al-Shaaibi et al., 2016) who reported that rats feeding high-fat diet showed hyperlipidemia. While, rats feeding on pomegranate peel extract ameliorated the elevation in serum lipid profile. Also, (Rahman et al., 2016) demonstrated that pomegranate peel extracts has a protective effect against carbon tetrachloride induced damage in rat's liver. It has a significant antioxidant activity. In addition, (Cheng et al., 2005) proved the hypolipidemic effect of 


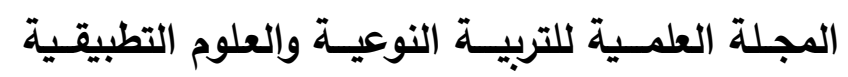

The Scientific Journal of Specific Education and Applied Sciences

polyphenolic extract from pomegranate peel. Rats fed with a highfat diet to induce hyperlipidemia and treatment with polyphenolic extract from pomegranate peel. The results showed reduction in the levels of TC/HDL-c ratio and serum LDL-c levels. The study concluded that pomegranate peel polyphenolic extract is effective in lowering serum and hepatic lipids.

Pomegranate juice had a protective effect due to the radical scavenging antioxidant compounds. The major antioxidant polyphenols in pomegranate juice include the ellagitannins and anthocyanin which have been shown to be the antioxidant responsible for resistance the free radicals (Gil et al., 2000).

The results of present study are in the line with (ElKhadragy, 2011) who reported that pomegranate juice has a hepato-protective role on carbon tetrachloride induced oxidative stress in rats. The antioxidant effect of flavonoids in pomegranate juice enhanced the process of regeneration; this may be because the destruction of free radicals, supplying a competitive substrate for unsaturated lipids in the membrane and accelerating the repair mechanism of damaged cell membrane. Also, (Aviram et al., 2000) reported that pomegranate juice consumption reduced lowdensity lipoproteins susceptibility capability to accumulation and retention. It increased the activity of serum paraoxonase (highdensity lipoproteins associated esterase that can protect against lipid peroxidation).

Table 2. Serum levels of alanine aminotransferase (ALT) and aspartate aminotransferase (AST) of the experimental rat groups.

\begin{tabular}{|c|c|c|c|c|}
\hline Parameters & control group & GJ & G3 & G4 \\
\hline ALT (U/L) & $30.30 \pm 4.69$ & $31.51 \pm 3.76$ & $79.33 \pm 22.13^{* *}$ & $40.60 \pm 5.51^{++}$ \\
\hline AST (U/L) & $69.53 \pm 7.76$ & $68.45 \pm 7.38$ & $135.32 \pm 26.65^{* *}$ & $73.71 \pm 11.31^{++}$ \\
\hline
\end{tabular}

Comparison between experimental groups as regard mean $\pm \mathrm{SD}(\mathrm{n}=10)$. Values are statistically significant at ${ }^{* *} \mathrm{p}<0.01$ versus $\mathrm{G} 1 ;{ }^{*} \mathrm{p}<0.05$ versus $\mathrm{G} 1 ;{ }^{++} \mathrm{p}<$ 0.01 versus G3; ${ }^{+} \mathrm{p}<0.05$ versus G3;. PJ: Pomegranate juice; HFD: high fat diet. 


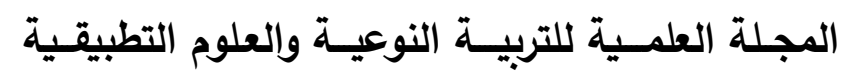

The Scientific Journal of Specific Education and Applied Sciences

To determine whether pomegranate juice could mitigate the HFD-induced liver injury, the levels of serum (ALT) and (AST) in the experimental groups were examined. As shown in table (2), the concentrations of serum (ALT) and (AST) in high fat diet group (G3) were significantly higher than that of the control group (G1). While, the rats fed high fat diet with pomegranate juice (G4) showed significantly reduction in the levels of (ALT) and (AST) as compared to high fat diet group (G3).

The elevated levels of (ALT) enzyme an indication to hepatocellular damage and systemic inflammation. NAFLD accompanied with increased liver (ALT) enzyme. The high levels of (AST) enzyme represent fatty liver pathogenesis (Mukherjee et al., 2013). The study results are consistent with (Saki et al., 2011) who reported that high-fat diet caused elevation in serum hepatic enzyme levels, (ALT) and (AST). These increase because the increase in the production of free radicals that initiate lipid peroxidation.

In addition, (Toklu et al., 2007) assayed the levels of serum aspartate aminotransferase (AST) and alanine aminotransferase (ALT) to evaluate liver functions. The AST and ALT levels in the serum, which were increased in liver fibrosis models, found to be considerably decreased and become near to normal levels after treatment with pomegranate peel. It was ascertained that pomegranate peel possesses protective effect for liver making it an important therapeutic agent in the treatment of fibrosis and oxidative damage.

The histopathological examination of liver tissues of the experimental groups are shown in fig (1). The histopathological examined hepatocytes and liver tissues for any abnormalities or fat droplets. Examination of livers sections obtained from rats received pomegranate juice (G2) were similar to the control group (G1) and showed normal histological structure of the liver. Examination of livers sections obtained from high fat diet group (G3) revealed histological changes in the form of fat droplets and necrosis. While, there were little fat droplets and no necrosis in hepatocytes in rats fed high fat diet with pomegranate juice group (G4), indicted that pomegranate juice had a protective effect against fat accumulation in the liver. Accumulation of fat in the liver can be in two forms: macro vesicular steatosis and micro 


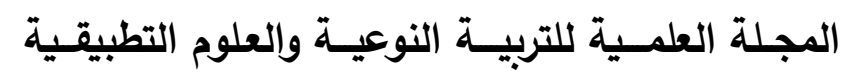

The Scientific Journal of Specific Education and Applied Sciences

vesicular steatosis . Macro vesicular steatosis due to large fat droplets which replace hepatocytes nuclei, micro vesicular steatosis due to small fat droplets which accumulate in the hepatocytes cytoplasm (Uhl, et al., 2014).

These results were supported by (Mukherjee et al., 2013) who reported that administration of pomegranate fruit extract showed reduced generation of (ROS) in hepatocytes, that the mechanism of antioxidant in the liver was up-regulated. There are a lot of health benefits in pomegranate polyphenols and it possess antioxidant properties which can protect the normal cells from various stimuli-induced oxidative stress and cell death. Also, (Kathirvel et al., 2013) reported that animals fed on high fat diet for 10 weeks, exhibited severe hepatic micro vesicular and macro vesicular steatosis which indicated severe NAFLD.
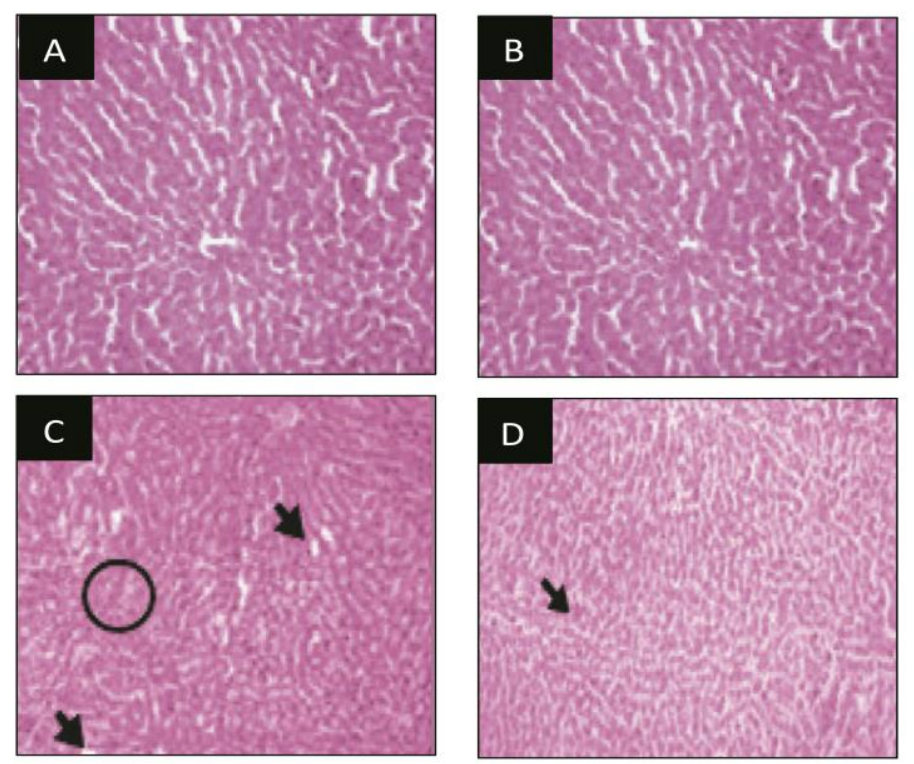

Figure1. Histopathological examination of liver tissues of the experimental rat groups. A: control group; B: Pomegranate juice; C: high fat diet; D: high fat diet with pomegranate juice. Arrows indicated fat droplets; circles indicate places of necrosis. 


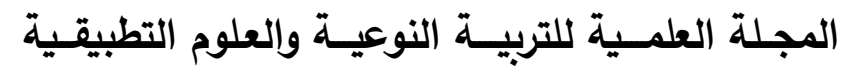

The Scientific Journal of Specific Education and Applied Sciences

Based on the results of the study, it was observed that daily administration of pomegranate juice can protect against developing changes caused by high fat diet and reduced the development of non-alcoholic fatty liver disease (NAFLD). These results in the line with (Gil et al., 2000) who reported that the activity of antioxidant in pomegranate components was higher than that of red wine and green tea, based on the evaluation of the free radicals scavenging activity and iron reducing capacity of the pomegranate juice.

Also, the results consistent with (Kaur et al., 2006) who reported that pretreatment with extract of pomegranate flower for a week had a protective effect against ferric nitrilotriacetate induced oxidative stress and hepatic injury. The protective effect may be due to antioxidant and hepatoprotective characteristics of pomegranate.

Furthermore, (Ahmed et al., 2014) who demonstrated that pomegranate peel extract and pomegranate juice had a strong antioxidant activity and free radical scavenging capability. In addition, (Xuan et al., 2014) elucidated that pomegranate extract administration significantly reduced high fat diet induced hyperlipidemia and hepatic lipid deposition. Pomegranate may be a useful nutrient for the curative of non-alcoholic fatty liver disease by improvement of mitochondrial function, removal oxidative stress and inflammation.

In an experimental study conducted by (Duygu et al., 2016) shows that pomegranate juice may prohibit acute hepatic damage related with Paracetamol considering antioxidant and histopathological changes. (Chidambara et al., 2002) reported that histopathological studies of the liver of different rat groups supported the protective effects of pomegranate peel extract by recovering the normal hepatic architecture.

\section{Conclusions:}

The results of the study concluded that pomegranate juice can protect against developing changes resulting from high fat diet and reduce the risk for incidence of fatty liver. Drinking pomegranate juice may be beneficial for people who are exposed to fatty liver disease or hypercholesterolemia. 


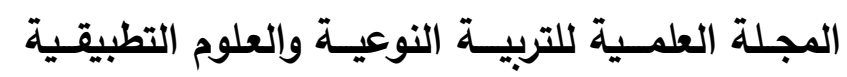

The Scientific Journal of Specific Education and Applied Sciences

\section{References:}

Ahmed, A.T.; Belal, S.K. and Elsaid Salem, A.G.(2014). Protective effect of pomegranate peel extract against diabetic induced renal histo-pathological changes in albino rats. IOSR J Dent Med Sci. 13: 94-105.

Agha, F.E.; Hasannane, M.M.; Omara, E.A.; Hasan, A.M. and El Tomy, S.A. (2013). Protective effect of Punica granatum peel extract against pentachlorophenol induced oxidative stress, cytogenetic toxicity and hepatic damage in rats. Aust J Basic Appl Sci. 7: 853-64.

Al-Shaaibi, S.N; Waly, M.I; Al-Subhi, L; Tageldin, M.H; AlBalushi, N.M. and Rahman, M.S. (2016). Ameliorative effects of pomegranate peel extract against dietary-induced nonalcoholic fatty liver in rats. Prev Nutr Food Sci. 21:1423.

Aviram, M.; Dornfeld, L.; Rosenblat, M; Volkova, N.; Kaplan, M. and Coleman, R. (2000). Pomegranate juice consumption reduces oxidative stress, atherogenic modifications to LDL, and platelet aggregation: studies in humans and in atherosclerotic apolipoprotein E-deficient mice. Am J Clin Nutr. 71: 1062-76.

Brunt, E.M. (2004). Nonalcoholic steatohepatitis. Semin Liver Dis. 24(1):3-20.

Charles, C. A.; Lucy, S. P.; Cicely, S. G.; Richmond, W. and Paul, C. Fu. (1974). Enzymatic Determination of Total Serum Cholesterol. CLIN. CHEM. 20(4): 470-75.

Cheng, S.; Guo, C.; Yang, J.; Wei, J.; Li. Y. and Xu, J. (2005). Experimental study on hypolipidemic effect of polyphenolic extract from pomegranate peel. Journal of Preventive Medicine of Chinese People's Liberation Army. 3:160-63.

Chidambara, M. K.; Jayaprakasha, GK. and Singh, RP.(2002). Studies on antioxidant activity of pomegranate (Punica granatum) peel extract using in vivo models. J Agric Food Chem. 50 (17): 4791-95.

Drury, R.A. and Wallington, E.A. (1980). Carlton histological techniques. Oxford university press. New York. Pronto. 206-25. 


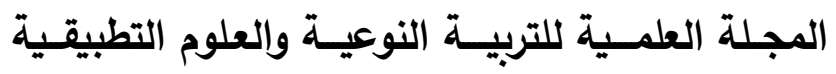

The Scientific Journal of Specific Education and Applied Sciences

Duygu, Ç.; Tuğba, K.; Duygu, K. D.; Meltem, Ö. and Mustafa, A. (2016). The protective effect of pomegranate juice in paracetamol-induced acute hepatotoxicity in rats. Turk Pediatri Ars. 51(2): 72-78

El-Khadragy. M.F. (2011). Hepatoprotective role of the pomegranate (Punica granatum) juice on carbon tetrachloride-induced oxidative stress in rats. Afr $\mathrm{J}$ Biol Sci.7:135-49.

Fossati, P. and Prencipe, L. (1982). Serum triglycerides determined colorimetrically with an enzyme that produces hydrogen peroxide. Clin Chem. 28(10):2077-80.

Gil, M.I; Tomás-Barberán, F.A; Hess-Pierce, B; Holcroft, D.M. and Kader, A.A. (2000). Antioxidant activity of pomegranate juice and its relationship with phenolic composition and processing. J Agric Food Chem. 48: 458189.

Iser, D. and Ryan, M. (2013). Fatty liver disease - a practical guide for GPs. Australian family physician. 42 (7): 444-47.

Jiayin, Y.; Min Z. and Minhu, C. (2011). Effect of silybin on high-fat-induced fatty liver in rats. Braz J Med Biol Res. 44:652-59.

Kathirvel, E.; Morgan, K.; French, S.W. andMorgan, T.R.(2013). Acetyl-L-carnitine and lipoic acid improve mitochondrial abnormalities and serum levels of liver enzymes in a mouse model of nonalcoholic fatty liver disease. Nutr Res. 33: 93241.

Kaur, G.; Jabbar, Z.; Athar, M. and Alam, M.S. (2006). Punica granatum (pomegranate) flower extract possesses potent antioxidant activity and abrogates fe-NTA induced hepatotoxicity in mice. Food Chem Toxicol. 44: 984-93.

Korish, A.A. and Arafah, M.M. (2013). Camel milk ameliorates steatohepatitis, insulin resistance and lipid peroxidation in experimental non-alcoholic fatty liver disease. BMC Complement Altern Med. 13: 264-83.

Lansky, E.P. and Newman, R.A. (2007). Punica granatum (pomegranate) and its potential for prevention and treatment 


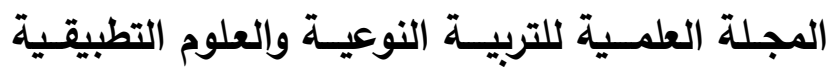

The Scientific Journal of Specific Education and Applied Sciences

of inflammation and cancer. J Ethnopharmacol. 109:177206.

Lim, D.W; Kim, Y.T; Jang ,Y.J; Kim, Y.E.and Han, D. (2013). Anti-obesity effect of Artemisia capillaris extracts in highfat diet-induced obese rats. Molecules. 18: 9241-52.

Lopes Virella, M.F.; Stone, P.; Ellis, S. and Colwell, J.A. (1977). Cholesterol determination in high-density lipoproteins separated by three different methods. Clin Chem. 23(5): 882-84.

Mudambi , S.R. and Rajagopal, M.V. (2007). Fundamentals of foods, nutrition and diet therapy. New Age International (P) Ltd., Publishers. Daryaganj, New Delhi. $5^{\text {th }}$ ed. 287-92.

Mukherjee, S.; Ghosh, S.; Choudhury, S.; Adhikary, A.; Manna, K.; Dey, S.; Sa, G.; Das, T. and Chattopadhyay, S.(2013). Pomegranate reverses methotrexate-induced oxidative stress and apoptosis in hepatocytes by modulating Nrf2-NF- $\kappa \mathrm{B}$ pathways. J Nutr Biochem. 24:2040-50.

Philp, G.R.; Forrest, H.N. and George, C.F. (1993). AIN-93 Purified Diets for Laboratory Rodents: Final Report of the American Institute of Nutrition Ad Hoc Writing Committee on the Reformulation of the AIN-76A Rodent Diet. J. Nutr. 123:1939-51.

Rahman Ibrahim, M.A.; Mahmoud Okail, H.A. and Mansour Emam, N.M. (2016). Ameliorative effects of pomegranate peel extract on hepatotoxicity induced by carbon tetrachloride in mice. Int J Res Stud Biosci. 4 : 23-31.

Rosenblat, M.; Hayek ,T. and Aviram, M. (2006). Anti-oxidative effects of pomegranate juice (PJ) consumption by diabetic patients on serum and on macrophages. Atherosclerosis. 187: 363-71.

Saki, N.; Saki, G.; Rahim,F.; Khoozani, A.S. and Nikakhlagh, S.(2011). Modulating effect of soy protein on serum cardiac enzymes in cholesterol-fed rats. Int J Med Med Sci. 3 : 39095.

Schumann, G. and Klauke, R. (2003). New IFCC reference procedures for the determination of catalytic activity concentrations of five enzymes in serum: preliminary upper 


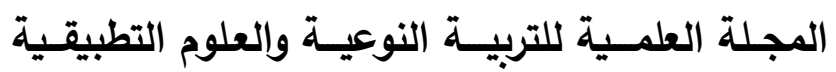

The Scientific Journal of Specific Education and Applied Sciences

reference limits obtained in hospitalized subjects. Clinica Chimica Acta. 327(1-2): 69-79.

Shepherd, J. (1994). Lipoprotein metabolism. An overview. Drugs. 47(Suppl 2):1-10.

Srivastava, L.M.; Das, N. and Sinha, S. (2002). Essentials of Practical Biochemistry. CBS Publishers \& Distributors.

Tan, Y.; Lao, W.; Xiao, L.; Wang, Z.; Xiao, W. and Kamal, M.A. (2013). Managing the combination of nonalcoholic fatty liver disease and metabolic syndrome with Chinese herbal extracts in high-fat-diet fed rats. Evid Based Complement Alternat Med. 2013: 306738-57.

Toklu, H.Z.; Dumlu, M.U. and Sehirli ,O. (2007). Pomegranate peel extract prevents liver fibrosis in biliary obstructed rats. Journal of Pharmacy and Pharmacology. 59(9):1287-95.

Uhl, P.; Fricker, G.; Haberkorn, U. and Mier W.(2014). Current status in the therapy of liver diseases. Int $\mathrm{J}$ Mol Sci. 15:7500-12.

Waller, R.A. and Duncan, D.B. (1969). A bays rule for the symmetric multiple comparison problem. Amer. State. Assoc. J. Dec., 1485-1503.

Xuan, Z.; Chunhong, Y.; Yujie, S.; Ke, C.; Jie ,X.; Xun, W.; Cong, C.; Cheng , L.; Yuan, L.; Jing, G.; Wentao, P.; Jialong, Z.; Fei ,Z.; Hao, L.; Jiankang, L. and Zhihui, F. (2014). Mitochondrial dysfunction in obesity-associated nonalcoholic fatty liver disease: the Protective effects of pomegranate with its active component punicalagin. Antioxid Redox Signal. 21(11): 1557-70. 


\section{المجلة العلمـية للتربيـة النوعيـة والعلوم التطبيقـية}

\section{The Scientific Journal of Specific Education and Applied Sciences}

تأثير عصير الرمان ضد الغذاء عالي الدهون المسبب لمرض الكبد الد الدي في الفئران

\section{سها محمد يوسف حسن}

تغذية وعلوم الأطعمة ـ قسم الاقتصاد المنزلي ـ كلية التربية النوعية ـ جامعة الفيوم

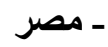

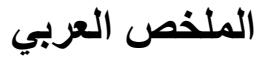

يهدف هذا البحث إلى دراسة تأثير عصبر الرمان ضد الغذاء

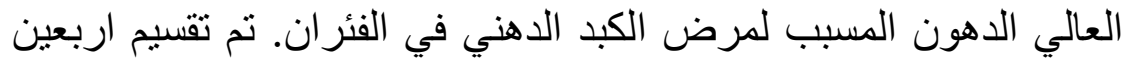

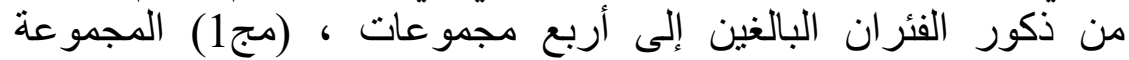

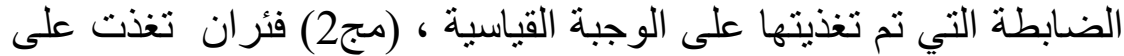

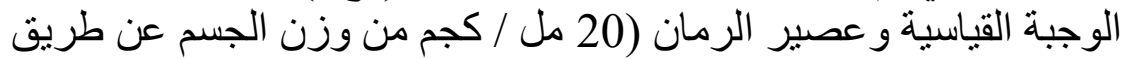

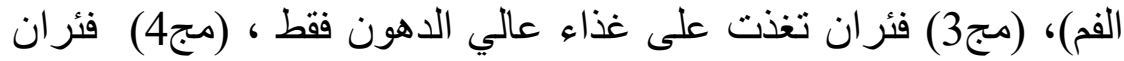

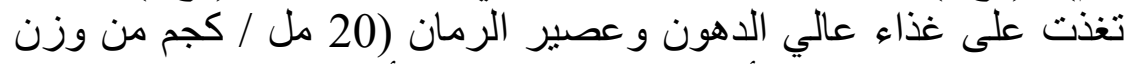

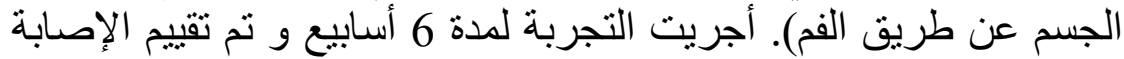

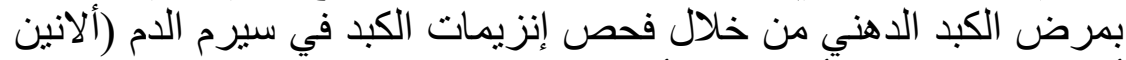

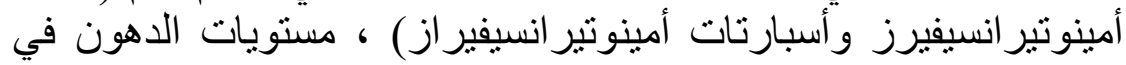
سيرم الدم (الكوليسترول الكلي ، البروتينات الدهنية عالئية النيات الكثافة و الدهون

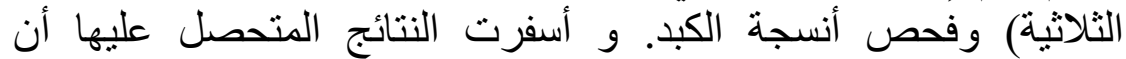

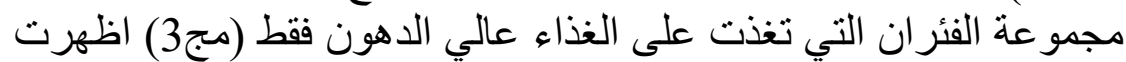

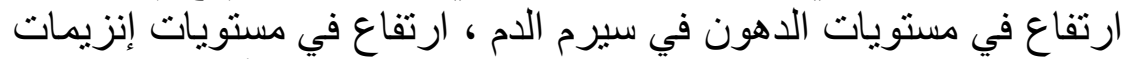

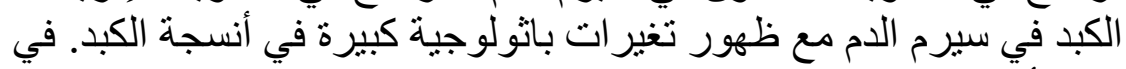

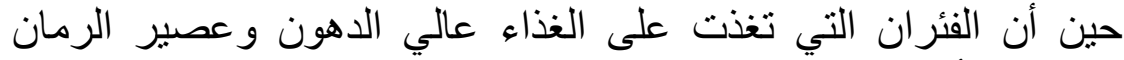

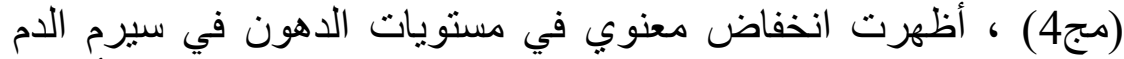

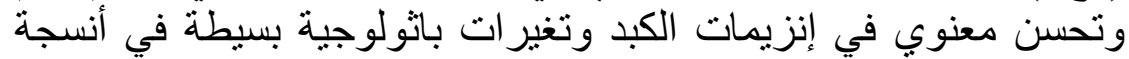

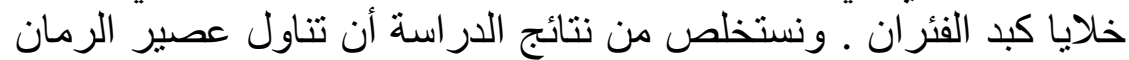

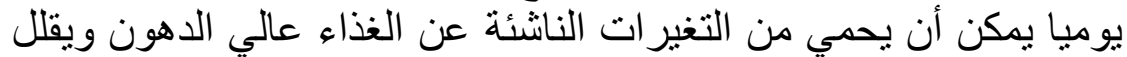

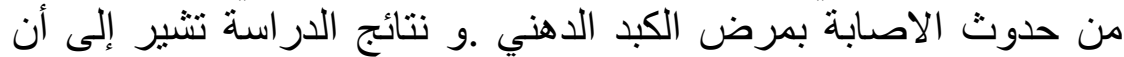

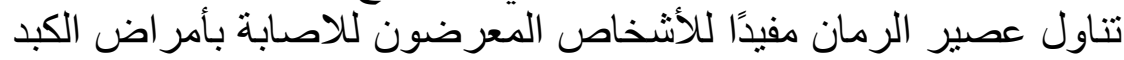

$$
\text { الدهني أو ارتفاع الكولسترول في الدان الدان. }
$$

الكلمات المفتاحية: عصير الرمان ـ الكبد الدهني ـ الغذاء عالي الدهون ـ الفئران 